\title{
An increase in MYC copy number has a progressive negative prognostic impact in patients with diffuse large B-cell and high-grade lymphoma, who may benefit from intensified treatment regimens
}

\begin{abstract}
Francesca Schieppati, ${ }^{1 *}$ Piera Balzarini,${ }^{2 *}$ Simona Fisogni, ${ }^{2}$ Alessandro Re,${ }^{1}$ Chiara Pagani, ${ }^{1}$ Nicola Bianchetti, ${ }^{1}$ Lorenzo Micheli, ${ }^{2}$ Angela Passi, ${ }^{1}$ Samantha Ferrari, ${ }^{1}$ Adriana Maifredi, ${ }^{1}$ Chiara Bottelli, ${ }^{1}$ Rossella Leopaldo, ${ }^{1}$ Vilma Pellegrini, ${ }^{2}$ Fabio Facchetti, ${ }^{2}$ Giuseppe Rossi ${ }^{1}$ and Alessandra Tucci ${ }^{1}$
\end{abstract}

${ }^{1}$ Department of Hematology, ASST Spedali Civili di Brescia and ${ }^{2}$ Department of Molecular and Translational Medicine, Section of Pathology, University of Brescia, Brescia, Italy

${ }^{*} F S$ and $P B$ contributed equally to this work.
1 YC translocations, a hallmark of Burkitt lymphoma, occur in $5-15 \%$ of diffuse large B-cell lymphoma, and have a negative prognostic impact. Numerical aberrations of $M Y C$ have also been detected in these patients, but their incidence and prognostic role are still controversial. We analyzed the clinical impact of MYC increased copy number on 385 patients with diffuse large B-cell lymphoma screened at diagnosis for $M Y C, B C L 2$, and $B C L 6$ rearrangements. We enumerated the number of $M Y C$ copies, defining as amplified those cases with an uncountable number of extra-copies. The prevalence of MYC translocation, increased copy number and amplification was $8.8 \%, 15 \%$, and $1 \%$, respectively. Patients with 3 or 4 gene copies, accounting for more than $60 \%$ of patients with $M Y C$ copy number changes, had a more favorable outcome compared to patients with $>4$ copies or translocation of MYC, and were not influenced by the type of treatment received as first-line. Stratification according to the number of MYC extra-copies showed a negative correlation between an increasing number of copies and survival. Patients with $>7$ copies or the amplification of $M Y C$ had the poorest prognosis. Patients with $>4$ copies of $M Y C$ showed a similar, trending towards worse prognosis compared to patients with MYC translocation. The survival of patients with $>4$ copies, translocation or amplification of MYC seemed to be superior if intensive treatments were used. Our study underlines the importance of fluorescence in situ hybridization testing at diagnosis of diffuse large B-cell lymphoma to detect the rather frequent and clinically significant numerical aberrations of $M Y C$.

\section{Introduction}

Diffuse large B-cell lymphoma (DLBCL) is a clinically and biologically heterogeneous group of diseases. ${ }^{1}$ The survival of patients with DLBCL has significantly improved since rituximab (R) was added to cyclophosphamide, doxorubicin, vincristine and prednisone (CHOP) therapy, and R-CHOP has now become the standard of care. The International Prognostic Index (IPI $)^{2}$ and the Revised-International Prognostic Index (R-IPI) $)^{3}$ are useful tools to stratify patients in different risk classes. However, despite this, $30-40 \%$ of these patients are not cured by R-CHOP or R-CHOP-like regimens. ${ }^{4}$ In the last two decades, much effort has been made to identify patients at high risk of treatment failure, using morphological subtyping, identification of cell of origin by gene expression profiling, ${ }^{7}$ BCL2 and MYC protein expression by immunohistochemistry, ${ }^{8}$ and molecular insights by genetic studies. ${ }^{9,10}$ In particular, different authors have demonstrated a negative prognostic impact of chromosomal aberration affecting the MYC gene locus in patients with
Ferrata Storti Foundation
Haematologica 2020
Volume 105(1):1369-1378

\section{Correspondence:}

FRANCESCA SCHIEPPATI

fschieppati@gmail.com

Received: April 6, 2019.

Accepted: August 8, 2019.

Pre-published: August 8, 2019.

doi:10.3324/haematol.2019.223891

Check the online version for the most updated information on this article, online supplements, and information on authorship \& disclosures: www.haematologica.org/content/105/5/1369

(C)2020 Ferrata Storti Foundation

Material published in Haematologica is covered by copyright. All rights are reserved to the Ferrata Storti Foundation. Use of published material is allowed under the following terms and conditions:

https://creativecommons.org/licenses/by-nc/4.0/legalcode. Copies of published material are allowed for personal or internal use. Sharing published material for non-commercial purposes is subject to the following conditions:

https://creativecommons. org/licenses/by-nc/4.0/legalcode, sect. 3. Reproducing and sharing published material for commercial purposes is not allowed without permission in writing from the publisher. 
DLBCL studied by interphase fluorescence in situ hybridization (FISH), both before ${ }^{11}$ and after $^{12,13}$ the introduction of rituximab. Overall, MYC genetic rearrangements have been described in 5-10\% DLBCL at diagnosis. ${ }^{10,11}$ The presence of dual translocations involving both MYC and BCL2 ("double-hit"), associated or not to the translocation of BCL6 ("triple-hit"), have shown a dismal clinical course. ${ }^{14}$ The importance of the molecular study of MYC, BCL2 and BCL6 status is highlighted by the updated World Health Organization (WHO) classification of 2016, which identifies a specific diagnostic category called "High Grade Lymphoma with MYC and BCL2 with or without BCL6 translocation", irrespective of the morphological subtype of DLBCL. In addition, preliminary studies suggest that the partner gene in the $M Y C$ translocation may also influence tumor behavior. ${ }^{15}$ In particular, MYC rearrangements with immunoglobulin genes, but not with other partner genes, seem to have a negative prognostic impact on patients with DLBCL treated with immunochemotherapy. ${ }^{16,17}$

Recent studies have revealed that also numerical alterations of MYC gene detected by FISH can occur in DLBCL. ${ }^{18}$ In the same way as chromosome translocations juxtapose oncogenes to the promoter of genes that are constitutively expressed, a gain of gene copy-number or the amplification of MYC may cause its over-transcription and protein over-expression leading to uncontrolled proliferation. ${ }^{19}$ Different studies have shown that numerical alterations of MYC may influence the outcome of patients with DLBCL, but their incidence and prognostic relevance is still controversial. ${ }^{19,20}$ Moreover, the definition of MYC copy number changes is not homogeneous across studies, where the terms "gain" and "amplification" are used to define different conditions. In the present study, we analyzed the frequency and the clinical outcome of patients with $M Y C$ numerical aberrations in the setting of DLBCL with particular emphasis on the number of MYC extracopies, on their frequency, and on their correlation with the clinical outcome in a consecutive series of DLBCL patients.

\section{Methods}

\section{Study design and participants}

In this retrospective, observational study, participants were enrolled between January 2011 and June 2016. Eligible patients were consecutive adults receiving a diagnosis of DLBCL during the study period. FISH study at diagnosis was performed on patients considered fit for treatment with curative intent. Tumors were classified according to the 2008 WHO Classification. No immunodeficiency-associated lymphomas were included. Disease burden was assessed by Ann-Arbor staging and IPI classification. ${ }^{2}$ All patients signed informed consent to provide material for biological studies. The study was conducted in accordance with good clinical practice guidelines and approved by the institutional ethical committee. All patients with DLBCL were treated with rituximab-containing immuno-chemotherapy programs. The following were considered standard dose regimens: $\mathrm{CHOP}$, and COMP (cyclophosphamide, vincristine, liposomal doxorubicin, and prednisone), whereas the following were considered intensified regimens: GMALL B-ALL/NHL 2002 protocol, ${ }^{21}$ and DA-EPOCH (dose adjusted etoposide, doxorubicin, cyclophosphamide vincristine, and prednisone). Autologous stem cell transplantation (ASCT) was used in approximately $25 \%$ of cases as intensification of first-line treatment, using BEAM/FEAM as conditioning regimens [carmustine (BCNU) or fotemustine, etoposide, cytarabine, melphalan followed by autologous stem cell infusion]. ASCT as intensification of a first-line treatment with R-CHOP was considered an intensified regimen.

\section{Interphase fluorescence in situ hybridization analysis}

Fluorescence in situ hybridization analysis was performed on $4-\mu \mathrm{m}$ sections of formalin-fixed paraffin-embedded (FFPE) tissue using break-apart DNA probes (Dako, Glostrup, Denmark) for cMYC (8q24), BCL2 (18q21) and BCL6 (3q27). FISH was carried out according to the manufacturer's guideline. FISH images were captured at x100 magnification and elaborated using the Genikon software (Nikon Instruments S.p.A., Italy). The presence of three or more red/green signals of $M Y C, B C L-2$ or $B C L-6$ was considered to indicate an increased copy number of these genes (namely MYC-ICN, BCL2-ICN, and BCL6-ICN). ${ }^{20}$ A "cloud-like" FISH pattern due to countless copies of MYC was defined as "amplification" (MYC-AMP) (Figure 1). We did not regularly use a chromosome 8 centromeric probe in this study. However, in 11 cases with MYC-ICN, single centromeric chromosome 8 probe (CEP8 SpectrumGreen, Abbott Molecular Inc., USA) was also used in order to exclude polysomy as cause of MYC-ICN.

\section{Immunohistochemistry}

Four-micron thick tissue sections were used for immunohistochemical staining for c-MYC (clone Y69, -Abcam; dilution 1:75), which was performed on a Bond III automated immunostainer (Leica Microsystem, Bannockburn, IL, USA) using controls in parallel. Diaminobenzidine was used to reveal the in situ hybridization (ISH) reaction and sections were counterstained with hematoxylin. A cut-off of $>40 \%$ was used for positive MYC expression by immunohistochemistry (IHC).

\section{Response criteria and statistical analysis}

Standard definitions of complete response (CR), progressionfree survival (PFS), and overall survival (OS) were used. ${ }^{22}$ Categorical data were compared using Fisher's exact test, whereas the Mann-Whitney test was used for continuous parameters. OS was measured from date of diagnosis to death from any cause, and PFS from the date of treatment start to the date of disease progression, relapse or death. The actuarial survival analysis was carried out according to the method described by Kaplan and Meier and the curves compared by the log-rank test with $95 \%$ confidence intervals (CI). ${ }^{23}$ Differences between the results of comparative tests were considered significant at two-sided $P<0.05$.

\section{Results}

\section{General clinical characteristics and outcome of the study population}

Of 504 patients diagnosed with DLBCL at our Institution, FISH was performed on 385 consecutive patients considered fit for treatment with curative intent. Tumors were classified according to the WHO 2008 Classification of Tumours of Haematopoietic and Lymphoid Tissues, as follows: 365 DLBCL not otherwise specified (NOS) (95\%), and 20 B-cell lymphoma, unclassifiable (BCLU), with features intermediate between diffuse large B-cell lymphoma and Burkitt lymphoma (5\%). Thirty-four $(8.3 \%)$ cases were transformed from a lowgrade lymphoma.

Ninety-five patients of the whole cohort of DLBCL had a structural or numerical aberration of MYC at FISH (25\%), 
and these constituted our study cohort. Figure 2 shows the flow diagram of the entire study population. The patients' main clinical characteristics at diagnosis are presented in Table 1, both for the whole cohort with FISH abnormalities and for the subgroups with either structural or numerical MYC aberrations. In addition, MYC protein expression by immunostaining was available for 52 patients, and was positive in $88 \%$ : among them, all patients with a translocation of MYC (MYC-T) over-expressed the MYC protein, whereas seven patients with numerical aberrations of MYC $(11 \%)$ showed $<40 \%$ expression of MYC protein by
IHC. Five patients initially considered fit for curative therapy received palliative/symptomatic treatment and were therefore excluded from the survival analyses. The remaining 90 patients received immuno-chemotherapy: standard dose in 46 patients or intensified regimens in 44 patients. Twenty-three patients received ASCT as intensification of first-line treatment. Median follow up was 38 months (range 0-79). A complete response (CR) was achieved in 55 patients $(61 \%)$. Overall, there was no difference in achievement of CR between patients receiving intensified and those receiving standard treatment $(57 \%$ vs. $65 \%$,
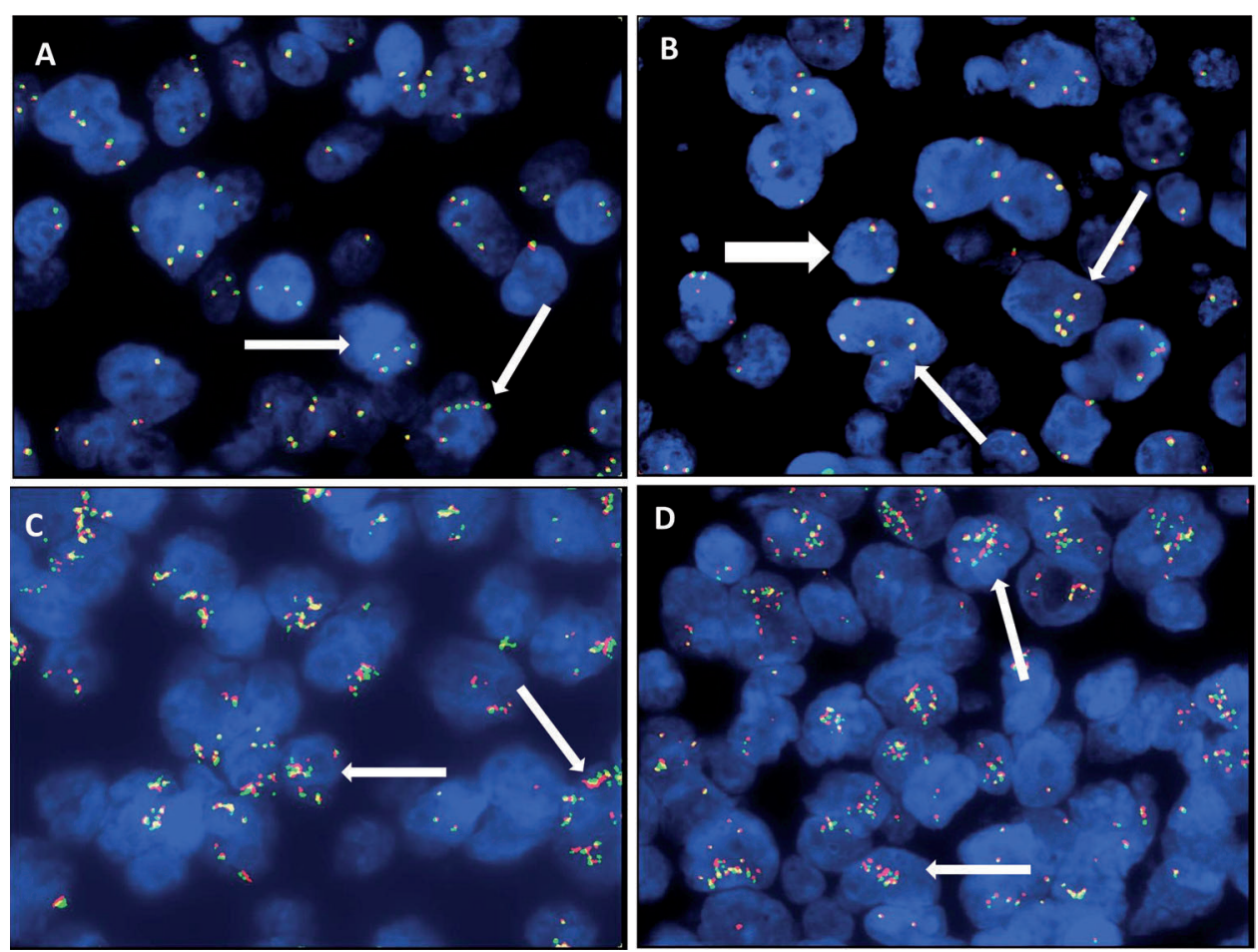

Figure 1. Numerical aberrations of MYC by fluorescence in situ hybridization (FISH). (A and B) Thin white arrows show MYC increased copy number (MYC-ICN); white thick arrow shows MYC wild type. (C and D) Thin white arrows show MYC amplification (MYC-AMP).

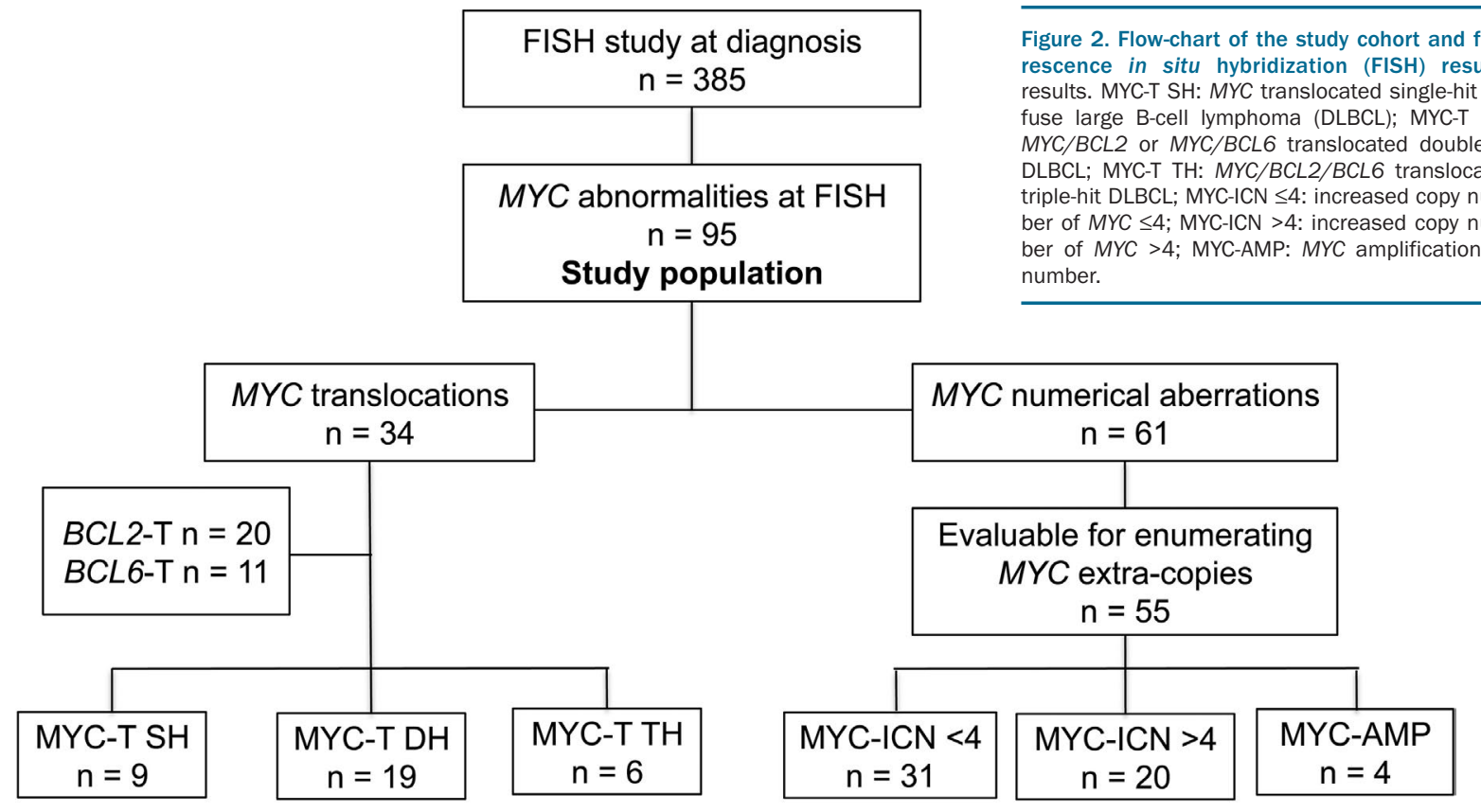


$P=0.41$ ). Median OS and PFS at three years were $58.8 \%$ and $54.8 \%$, respectively, with no significant differences between the groups treated with intensified or standard regimens ( $P=0.93$ and $P=0.69$, respectively). Outcome was similar in the two groups receiving standard or intensified regimens, despite the different treatment schemes. Twenty patients received R-COMP due to age over 70 years or cardiac dysfunction; none received consolidation with ASCT. The other 26 patients in the standard regimen arm received $\mathrm{R}-\mathrm{CHOP}$, and no differences in the outcome were seen between patients treated with the R-COMP and those treated with R-CHOP (OS $73 \%$ vs. $53 \%, P=0.2$ ). In the intensified group, one patient with a transformed lymphoma received R-ESHAP and ASCT due to the risk of cardiotoxicity related to prior anthracycline therapy. There was no significant difference in $O S$ among patients receiving R-CHOP-like + ASCT, GMALL-like \pm ASCT, or R-DA$\mathrm{EPOCH} \pm \mathrm{ASCT}(\mathrm{OS} 69 \%$ vs. $51 \%$ vs. $69 \%$, respectively, $P=0.8)$.

Table 1. Clinical characteristics of the patients with structural and numerical aberrations of MYC at fluorescence in situ hybridization.

\begin{tabular}{|c|c|c|c|}
\hline & $\begin{array}{c}\text { All patients } \\
(n=95) \\
n(\%)\end{array}$ & $\begin{array}{c}\text { MYC-T } \\
(n=34) \\
n(\%)\end{array}$ & $\begin{array}{c}\text { MYC-ICN/ } \\
\text { MYC AMP } \\
(n=61) \\
n(\%)\end{array}$ \\
\hline Age, median (range) & $67(21-88)$ & $66.5(27-88)$ & $67(21-84)$ \\
\hline Male sex & $63(66)$ & $24(71)$ & $39(64)$ \\
\hline Ann Arbor stage III-IV & $76(80)$ & $30(88)$ & $46(75)$ \\
\hline $\begin{array}{l}\text { IPI High intermediate/ } \\
\text { High risk }\end{array}$ & $66(69)$ & $24(71)$ & $42(69)$ \\
\hline IHC MYC positivity & $\begin{array}{c}\mathbf{n}=\mathbf{5 2} \\
46(88)\end{array}$ & $\begin{array}{c}\mathbf{n}=\mathbf{2 4} \\
24(100)\end{array}$ & $\begin{array}{r}\mathbf{n}=\mathbf{2 8} \\
21(75)\end{array}$ \\
\hline $\begin{array}{l}\text { Histopathology } \\
\text { DLBCL, NOS } \\
\text { BCLU }\end{array}$ & $\begin{array}{l}87(92) \\
8(8)\end{array}$ & $\begin{array}{l}27(79) \\
7(21)\end{array}$ & $\begin{array}{c}60(98) \\
1(2)\end{array}$ \\
\hline $\begin{array}{l}\text { BCL2 and BCL6 status } \\
\text { BCL2-T } \\
\text { BCL6-T } \\
\text { BCL2-ICN } \\
\text { BCL6-ICN }\end{array}$ & $\begin{array}{l}34(36) \\
29(31) \\
23(24) \\
21(22)\end{array}$ & $\begin{array}{l}20(59) \\
2(6) \\
11(32) \\
5(15)\end{array}$ & $\begin{array}{l}14(23) \\
27(44) \\
12(20) \\
16(27)\end{array}$ \\
\hline $\begin{array}{l}\text { Treatment regimen } \\
\text { Standard } \\
\text { R-CHOP/R-CHOP-like } \\
\text { - R-CHOP } \\
\text { - R-COMP }\end{array}$ & $\begin{array}{l}46(48) \\
26(27) \\
20(21)\end{array}$ & $\begin{array}{l}9(26) \\
6(17) \\
3(9)\end{array}$ & $\begin{array}{l}37(61) \\
20(33) \\
17(28)\end{array}$ \\
\hline $\begin{array}{l}\text { Intensified } \\
\text { GMALL-like } \pm \text { ASCT } \\
\text { R-DA-EPOCH } \pm \text { ASCT } \\
\text { R-CHOP/R-CHOP-like + ASCT } \\
\text { - R-CHOP + ASCT } \\
\text { - R-ESHAP + ASCT }\end{array}$ & $\begin{array}{c}44(46) \\
15(23) \\
13(14) \\
16(17) \\
15(16) \\
1(1)\end{array}$ & $\begin{array}{l}22(65) \\
10(29) \\
10(29) \\
2(6) \\
1(3) \\
1(3)\end{array}$ & $\begin{array}{c}22(36) \\
5(8) \\
3(5) \\
14(23) \\
14(23) \\
0\end{array}$ \\
\hline Palliative & $5(5)$ & $3(9)$ & $2(3)$ \\
\hline Total ASCT consolidation & $23(24)$ & $8(23)$ & $15(25)$ \\
\hline $\begin{array}{l}\text { Response } \\
\text { CR } \\
\text { PR } \\
\text { NR/disease progression }\end{array}$ & $\begin{array}{r}\mathbf{n}=\mathbf{9 0} \\
55(61) \\
12(13) \\
23(26)\end{array}$ & $\begin{array}{c}\mathbf{n}=\mathbf{3 1} \\
18(58) \\
4(13) \\
9(29)\end{array}$ & $\begin{array}{c}\mathbf{n}=\mathbf{5 9} \\
37(63) \\
8(14) \\
14(24)\end{array}$ \\
\hline
\end{tabular}

DLBCL: diffuse large B-cell lymphoma; NOS: not otherwise specified;BCLU: B-cell lymphoma, unclassifiable; IPI: International Prognostic Index; IHC: immunohistochemistry; ASCT: autologous stem cell transplantation; CR: complete response; PR: partial response; NR: no response; n: number.

\section{MYC, BCL2 and BCL6 translocations}

A MYC translocation (MYC-T) by FISH study was observed in 34 patients (8.8\%). With respect to BCL2 and $B C L 6, M Y C$ translocation occurred as a single-hit (SH) aberration in 9 of 34 patients $(26 \%)$, whereas $19(56 \%)$ and 6 (18\%) patients had a "double-hit" (DH) and "triple-hit" (TH) DLBCL, respectively. The clinical characteristics in terms of age, gender, histopathology, MYC protein expression by IHC, Ann Arbor and IPI stage were not significantly different among patients with SH, DH or TH DLBCL (Table 2). Three patients who received palliative/symptomatic treatment were excluded from the survival analyses. Overall, nine patients were treated with a standard regimen and 22 with an intensified regimen, with similar distribution among the $\mathrm{SH}, \mathrm{DH}$ and TH DLBCL groups. After a median follow up of 33 months, the 2.5 -year OS was similar among $\mathrm{SH}, \mathrm{DH}$, and TH DLBCL patients.

\section{Numerical aberrations MYC by fluorescence in situ hybridization}

We observed an increased number of $M Y C$ gene copies $(16 \%)$ in tumor samples from 61 patients negative for MYC translocations. Fifty-seven cases (15\%) were referred to as to "increased copy number of $M Y C$ " (MYCICN) DLBCL, while four cases (1\%) showed amplification of MYC (MYC-AMP) (Figure 1). The exact number of

Table 2. Clinical characteristics of the patients with single-hit (SH), double-hit (DH) or triple-hit (TH) diffuse large B-cell lymphoma at fluorescence in situ hybridization.

\begin{tabular}{|c|c|c|c|c|}
\hline & $\begin{array}{c}\text { MYC-T SH } \\
(n=9) \\
n(\%)\end{array}$ & $\begin{array}{c}\text { MYC-T DH } \\
(n=19) \\
n(\%)\end{array}$ & $\begin{array}{c}\text { MYG-T TH } \\
\begin{array}{c}(n=6) \\
n(\%)\end{array}\end{array}$ & $\boldsymbol{P}$ \\
\hline Age, median (range) & $\begin{array}{c}71 \\
(29-74)\end{array}$ & $\begin{array}{c}63 \\
(29-88)\end{array}$ & $\begin{array}{c}62 \\
(58-83)\end{array}$ & 0.71 \\
\hline Male gender & $4(44)$ & $15(79)$ & $5(83)$ & 0.13 \\
\hline Ann Arbor stage III-IV & $7(78)$ & $18(95)$ & $5(83)$ & 0.39 \\
\hline $\begin{array}{l}\text { IPI High intermediate/ } \\
\text { High risk }\end{array}$ & $8(89)$ & $12(63)$ & $4(67)$ & 0.36 \\
\hline IHC MYC positivity & $\begin{array}{c}\mathbf{n}=\mathbf{5} \\
5(100)\end{array}$ & $\begin{array}{c}\mathbf{n}=\mathbf{1 5} \\
15(100)\end{array}$ & $\begin{array}{c}\mathbf{n}=\mathbf{4} \\
4(100)\end{array}$ & - \\
\hline $\begin{array}{l}\text { Histopathology } \\
\text { DLBCL, NOS } \\
\text { BCLU }\end{array}$ & $\begin{array}{l}7(78) \\
2(22)\end{array}$ & $\begin{array}{l}15(79) \\
4(21)\end{array}$ & $\begin{array}{l}5(83) \\
1(17)\end{array}$ & 0.96 \\
\hline
\end{tabular}

Treatment regimen

Standard

R-CHOP/R-CHOP-like

Intensified

$\begin{array}{lcccc}\text { GMALL-like } \pm \text { ASCT } & 4(45) & 5(27) & 1(17) & 0.46 \\ \text { R-DA-EPOCH } \pm \text { ASCT } & 0 & 8(42) & 2(33) & 0.07 \\ \text { R-CHOP/R-CHOP-like + ASCT } & 1(11) & 1(5) & 0 & 0.65 \\ & & & & \\ \text { Palliative } & 2(22) & 1(5) & 0 & 0.23 \\ \text { Total ASCT consolidation } & 1(11) & 6(36) & 1(17) & 0.44 \\ \text { Response } & \mathbf{n = 7} & \mathbf{n = 1 8} & \mathbf{n = 6} & \\ \text { CR } & 5(71) & 9(50) & 4(67) & 0.69 \\ \text { PR } & 0 & 4(22) & 0 & 0.16 \\ \text { NR/disease progression } & 2(29) & 5(28) & 2(33) & 0.89 \\ \text { 2.5-year OS } & 47 \% & 58 \% & 62 \% & 0.96\end{array}$

DLBCL: diffuse large B-cell lymphoma; NOS: not otherwise specified; BCLU: B-cell lymphoma, unclassifiable; IPI: International Prognostic Index; IHC: immunohistochemistry; ASCT: autologous stem cell transplantation; $\mathrm{CR}$ : complete response; PR: partial response; NR: no response; OS: overall survival; n: number. 
extra-copies (EC) of MYC was not assessable in six cases. In the remaining 51, 3-10 gene copies per cell were found in at least $50 \%$ of the analyzed nuclei. In detail, the distribution of MYC gene copies in the MYC-ICN cases was: 3 copies in 12 cases $(24 \%), 4$ copies in 19 (37\%), 5 copies in $8(15 \%), 6$ copies in $4(8 \%), 7$ copies in $5(10 \%)$, and $8-10$ copies in $3(6 \%)$. Of note, more than $60 \%$ of cases presented 3-4 copies of $M Y C$. Since ICN aberration was identified during routine MYC analysis for which the breakapart probe is regularly used in our laboratory, information on the copies of chromosome 8 was available in only 11 cases showing MYC-ICN, where a single centromeric chromosome 8 probe was also used. No abnormal copies of chromosome 8 were detected in any of these cases, whereas identical MYC-ICN was found, thus excluding polysomy as cause of MYC-ICN.

An excess of copies of BCL2 (BCL2-ICN) and BCL6 (BCL6-ICN) was also found in these cases (in $44 \%$ and $27 \%$, respectively), whereas BCL2 and BCL6 translocations (BCL2-T and BCL6-T) were observed in 23\% and $20 \%$ of cases with numerical aberrations of $M Y C$, respectively (Table 1).

\section{Clinical impact of numerical and structural aberrations of MYC}

The overall prognosis of patients with $M Y C$ numerical aberrations showed a negative correlation between increasing number of $M Y C$ copies and survival (Figure 3). Patients with MYC-ICN $\leq 4$ had a more favorable outcome, with 2.5-year OS of 73\% (95\% CI: 50-84) compared to $30 \%$ (95\% CI: $15-43)$ of the patients with MYC-ICN >4 $(P=0.007)$ (Figure 3A). Having MYC-ICN $>7$ or MYC-AMP was associated with the worst prognosis, with a median $\mathrm{OS}$ of 8 and 8.5 months, respectively $(P=0.0008)$ (Figure $3 \mathrm{~B})$. When comparing the outcome of patients with MYCICN $\leq 4$ and MYC-ICN >4 with the outcome of patients with MYC-T or MYC-AMP, the presence of MYC-ICN $\leq 4$ was associated with a better outcome $(P=0.01)$ (Figure 3C), while patients with MYC-ICN $>4$ had no significant difference in OS compared to MYC-T $(P=0.1)$, and both these groups of patients had a better survival compared to MYC-AMP ( $P=0.05$ and $P=0.01$, respectively).

The demographic and clinical characteristics of the patients with MYC-ICN $\leq 4, \mathrm{MYC}-\mathrm{ICN}>4$, MYC-T, and MYC-AMP in terms of age, gender, histopathology, MYC
A

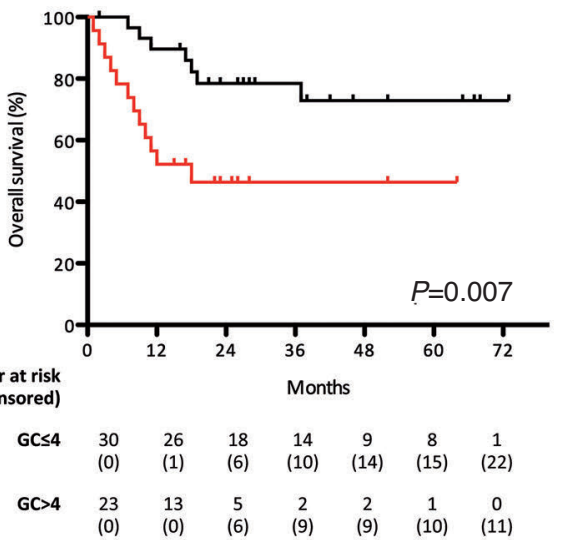

C

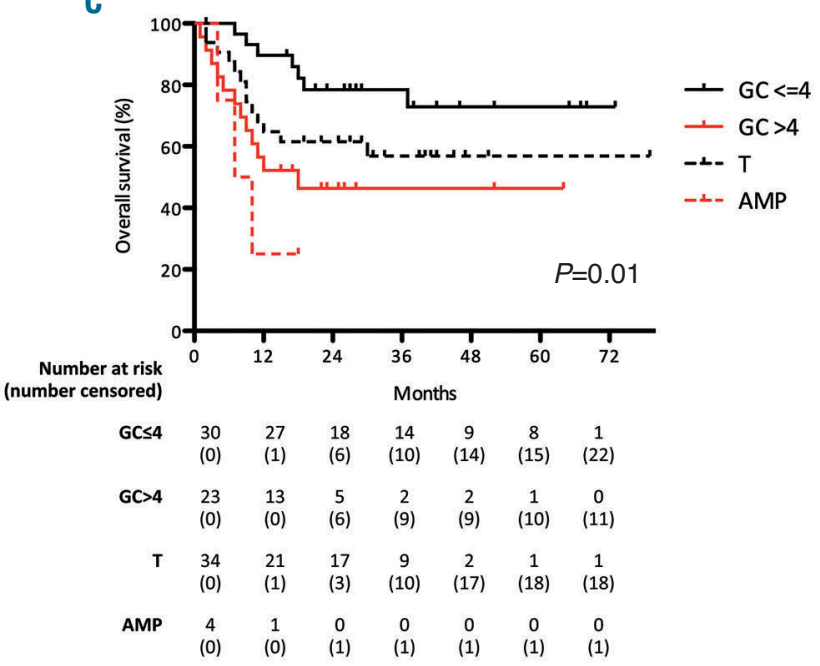

B

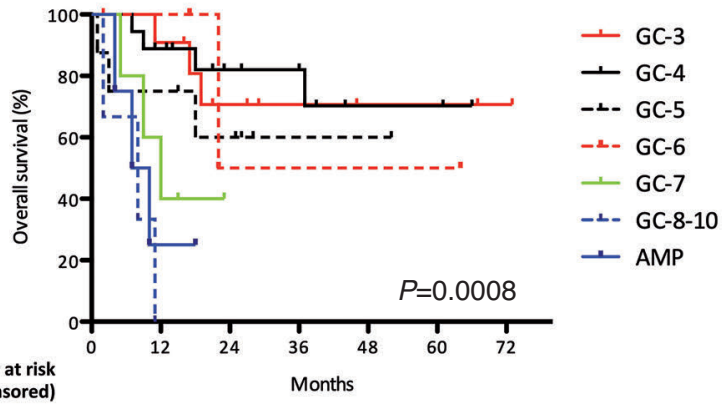

(number censored)

$\begin{array}{cccccccc}\text { GC-3 } & 12 & 10 & 6 & 4 & 3 & 3 & 1 \\ & (0) & (1) & (3) & (5) & (6) & (6) & (8) \\ \text { GC-4 } & 18 & 15 & 9 & 8 & 3 & 3 & 0 \\ & (0) & (1) & (6) & (7) & (11) & (11) & (14) \\ \text { GC-5 } & 8 & 6 & 4 & 1 & 1 & 0 & 0 \\ & (0) & (0) & (1) & (4) & (4) & (5) & (5) \\ \text { GC-6 } & 3 & 3 & 1 & 1 & 1 & 1 & 0 \\ & (0) & (0) & (1) & (1) & (1) & (1) & (2) \\ \text { GC-7 } & 5 & 3 & 0 & 0 & 0 & 0 & 0 \\ & (0) & (0) & (2) & (2) & (2) & (2) & (2) \\ \text { GC-8-10 } & 3 & 0 & 0 & 0 & 0 & 0 & 0 \\ & (0) & (0) & (0) & (0) & (0) & (0) & (0) \\ \text { AMP } & 4 & 1 & 0 & 0 & 0 & 0 & 0 \\ & (0) & (0) & (1) & (1) & (1) & (1) & (1)\end{array}$

Figure 3. Negative correlation between increasing number of MYC copies and survival. (A) Kaplan-Meier curve comparing 2.5 year overall survival (OS) of patients with MYC-ICN $\leq 4$ and patients with MYC-ICN $>4$. (B) Negative correlation between increasing number of MYC copies and survival: patients with MYC gene copies (MYC-GC) $>7$ and MYC-AMP showed the worse prognosis. (C) Comparison of the outcome of patients with MYC-ICN $\leq 4$ and MYC-ICN $>4$ with patients with MYC translocation (MYC-T) or MYC-AMP: while MYC-ICN $\leq 4$ conferred the best outcome, patients with MYC-ICN $>4$ had no significant difference in OS compared to MYC-T, and both these groups of patients had a better survival compared to MYC-AMP; GC: gene copies. 
protein expression by IHC, Ann Arbor and IPI stage, were not significantly different, except that patients with a histological diagnosis of BCLU clustered in the MYC-T and MYC-AMP groups $(P=0.03$ ) (Table 3$)$. Notably, all patients with MYC-AMP showed aggressive clinical features, although one did not show MYC protein overexpression by IHC.

The treatment type and the response to treatment in each FISH category are reported in Table 3. Patients with MYC-ICN preferentially received standard treatment (61\% MYC-ICN $\leq 4$ and 65\% MYC-ICN >4, respectively, $P=0.008)$, unlike patients with MYC-T and MYC-AMP who received an intensified regimen in $65 \%$ and $75 \%$ of cases, respectively $(P=0.02)$.

Patients with MYC-ICN $\leq 4$ had a higher overall response rate (ORR) and complete response rate (CRR) compared to the other FISH groups (ORR 93\% vs. 59\%, P=0.0009; CRR $73 \%$ vs. $57 \%, P=0.16$ ), and also a significantly lower pro- gression rate ( $7 \%$ vs. $41 \%, P=0.0009)$. In the MYC-ICN $\leq 4$ subgroup, there was neither a difference in terms of ORR and CRR achievement, nor a significant advantage in terms of OS and PFS between patients treated with standard or intensified regimens. At a median follow up of 3.5 years, OS was $73 \%$ and $70 \%$, respectively. In the MYC-T group, ORR was similar in patients treated with standard or intensive induction therapy, and CRR was slightly higher in the intensified-regimen group (64\% vs. 55\%) (Table 3).

Patients with MYC-ICN $>4$ and MYC-T receiving a first-line intensified regimen showed a non-significant trend toward a better outcome (2.5-year OS of $40 \%$ for standard treatment vs. $60 \%$ for intensified treatment in MYC-ICN >4; OS of $53 \%$ for standard treatment vs. $65 \%$ for intensified treatment in MYC-T). The same trend was seen combining MYC-AMP group with MYC-ICN $>4$ and MYC-T groups (2.5-year OS of $32 \%$ for standard vs. $57 \%$ for intensified treatment).

Table 3. Clinical characteristics of the patients with MYC-ICN $\leq 4$, MYC-ICN $>4$, MYC-T, and MYC-AMP.

\begin{tabular}{|c|c|c|c|c|c|}
\hline All patients & $\begin{array}{c}\text { MYC-ICN } \leq 4 \\
(n=31) \\
n(\%)\end{array}$ & $\begin{array}{c}\text { MYC-ICN >4 } \\
\begin{array}{c}(n=20) \\
n(\%)\end{array}\end{array}$ & $\begin{array}{c}\text { MYC-T } \\
(n=34) \\
n(\%)\end{array}$ & $\begin{array}{l}\text { MYC-AMP } \\
\begin{array}{c}(n=4) \\
n(\%)\end{array}\end{array}$ & $\boldsymbol{P}$ \\
\hline Age, median (range) & $65(21-84)$ & $73(30-81)$ & $66.5(27-88)$ & $66(57-73)$ & 0.81 \\
\hline Male gender, n. (\%) & $20(65)$ & $9(45)$ & $24(72)$ & $4(100)$ & 0.15 \\
\hline Ann Arbor stage III-IV & $22(71)$ & $15(75)$ & $30(91)$ & $4(100)$ & 0.77 \\
\hline IPI High intermediate/ High risk & $19(61)$ & $16(80)$ & $24(72)$ & $4(100)$ & 0.31 \\
\hline IHC MYC positivity & $\begin{array}{l}\mathbf{n}=\mathbf{1 3} \\
9(69)\end{array}$ & $\begin{array}{l}\mathbf{n}=\mathbf{1 1} \\
9(81)\end{array}$ & $\begin{array}{c}\mathbf{n}=\mathbf{2 4} \\
24(100)\end{array}$ & $\begin{array}{l}\mathbf{n}=\mathbf{3} \\
2(66)\end{array}$ & 0.21 \\
\hline $\begin{array}{l}\text { Histopathology } \\
\text { DLBCL, NOS } \\
\text { BCLU }\end{array}$ & $\begin{array}{c}31(100) \\
0\end{array}$ & $\begin{array}{c}20(100) \\
0\end{array}$ & $\begin{array}{l}27(82) \\
6(18)\end{array}$ & $\begin{array}{l}3(75) \\
1(25)\end{array}$ & $\begin{array}{c}0.06 \\
\mathbf{0 . 0 3}\end{array}$ \\
\hline \multicolumn{6}{|l|}{ Treatment regimen } \\
\hline $\begin{array}{l}\text { Standard } \\
\text { R-CHOP/R-CHOP-like }\end{array}$ & $19(61)$ & $13(65)$ & $9(26)$ & $1(25)$ & 0.008 \\
\hline $\begin{array}{l}\text { Intensified } \\
\text { GMALL-like } \pm \text { ASCT } \\
\text { R-DA-EPOCH } \pm \text { ASCT } \\
\text { R-CHOP/R-CHOP-like + ASCT }\end{array}$ & $\begin{array}{c}11(35) \\
1(3) \\
0 \\
10(33)\end{array}$ & $\begin{array}{l}6(30) \\
2(10) \\
2(10) \\
2(10)\end{array}$ & $\begin{array}{l}22(65) \\
10(29) \\
10(29) \\
2(6)\end{array}$ & $\begin{array}{l}3(75) \\
1(25) \\
1(25) \\
1(25)\end{array}$ & $\begin{array}{c}0.02 \\
0.02 \\
0.008 \\
0.03\end{array}$ \\
\hline Palliative & $1(3)$ & $1(5)$ & $3(9)$ & 0 & 0.74 \\
\hline Total ASCT consolidation & $10(33)$ & $2(11)$ & $8(23)$ & $1(25)$ & 0.38 \\
\hline $\begin{array}{l}\text { Response } \\
\text { ORR } \\
\text { Standard } \\
\text { Intensified }\end{array}$ & $\begin{array}{c}\mathbf{n}=\mathbf{3 0} \\
28(93) \\
17 / 19(89) \\
11 / 11(100)\end{array}$ & $\begin{array}{c}\mathbf{n}=\mathbf{1 9} \\
11(63) \\
8 / 13(61) \\
3 / 6(50)\end{array}$ & $\begin{array}{c}\mathbf{n}=\mathbf{3 1} \\
20(64) \\
6 / 9(67) \\
14 / 22(64)\end{array}$ & $\begin{array}{c}\mathbf{n}=\mathbf{4} \\
1(25) \\
0 \\
1 / 3(33)\end{array}$ & $0.0009 *$ \\
\hline $\begin{array}{l}\text { CR } \\
\text { Standard } \\
\text { Intensified }\end{array}$ & $\begin{array}{c}22(73) \\
14 / 19(74) \\
8 / 11(73)\end{array}$ & $\begin{array}{l}11(58) \\
8 / 13(61) \\
3 / 6(50)\end{array}$ & $\begin{array}{c}19(61) \\
5 / 9(55) \\
14 / 22(64)\end{array}$ & $\begin{array}{l}1(25) \\
0 / 1(0) \\
1 / 3(33)\end{array}$ & $0.16^{*}$ \\
\hline $\begin{array}{l}\text { PR } \\
\text { Standard } \\
\text { Intensified }\end{array}$ & $\begin{array}{c}6(20) \\
3 / 19(16) \\
3 / 11(27)\end{array}$ & $\begin{array}{c}0 \\
0 / 13 \\
0 / 6\end{array}$ & $\begin{array}{c}1(3) \\
1 / 9(11) \\
0 / 22\end{array}$ & $\begin{array}{c}0 \\
0 / 1 \\
0 / 3\end{array}$ & $0.03^{*}$ \\
\hline $\begin{array}{l}\text { NR/disease progression } \\
\text { Standard } \\
\text { Intensified }\end{array}$ & $\begin{array}{c}2(7) \\
2 / 19(10) \\
0 / 11(0)\end{array}$ & $\begin{array}{c}8(42) \\
5 / 13(38) \\
3 / 6(50)\end{array}$ & $\begin{array}{c}11(36) \\
3 / 9(33) \\
8 / 22(36)\end{array}$ & $\begin{array}{c}3(75) \\
1 / 1(100) \\
2 / 3(67)\end{array}$ & $0.0009 *$ \\
\hline
\end{tabular}

DLBCL: diffuse large B-cell lymphoma; NOS: not otherwise specified; BCLU: B-cell lymphoma, unclassifiable; IPI: International Prognostic Index; IHC: immunohistochemistry; ASCT: autologous stem cell transplantation; ORR: overall response rate; $C R$ : complete response; PR: partial response; NR: no response; n: number. * Overall response (OR), CR, PR and NR/disease progression rates of MYC-ICN $<4$ compared to the combination of other fluorescence in situ hybridization (FISH) groups. 
Among intensified regimens, in MYC-T and MYC-AMP subgroups, patients treated with R-DA-EPOCH showed an advantage in ORR compared to patients treated with GMALL B-ALL/NHL 2002 protocol or R-CHOP followed by ASCT (ORR $82 \%$ vs. $36 \%, P=0.04$ ), and a trend toward a better survival was also seen (2.5-year OS of $81 \%$ vs. $46 \%, P=0.08$ ) (Figure 4). Five patients initially considered fit for curative treatment and tested by FISH, were eventually treated with palliative care due to rapidly worsening clinical conditions. Palliative regimens were single-agent cyclophosphamide for three patients, and single-agent vincristine for two patients; among these five patients, three had MYC-T (1 double-hit MYC-T/BCL2-T, 2 single- hit lymphomas), one MYC-ICN $\leq 4$, and one MYC-ICN>4 They experienced a dismal outcome irrespective of MYC status (median survival of 2 months for the MYC-T group and 1 month for each of the other 2 patients, $P=0.7$ ) (data not shown).

Finally, we analyzed the impact of BCL2 and BCL6 numerical and structural aberrations on the outcome of patients with numerical aberrations of MYC (MYCICN/MYC-AMP). BCL2-ICN did not influence patient survival, which was very similar to patients with wild-type (WT) BCL2 (2.5-year OS $70 \%$ vs. 69\%, respectively). However, BCL2-T negatively influenced patient outcome compared to BCL2-WT and BCL2-ICN patients (2.5-year

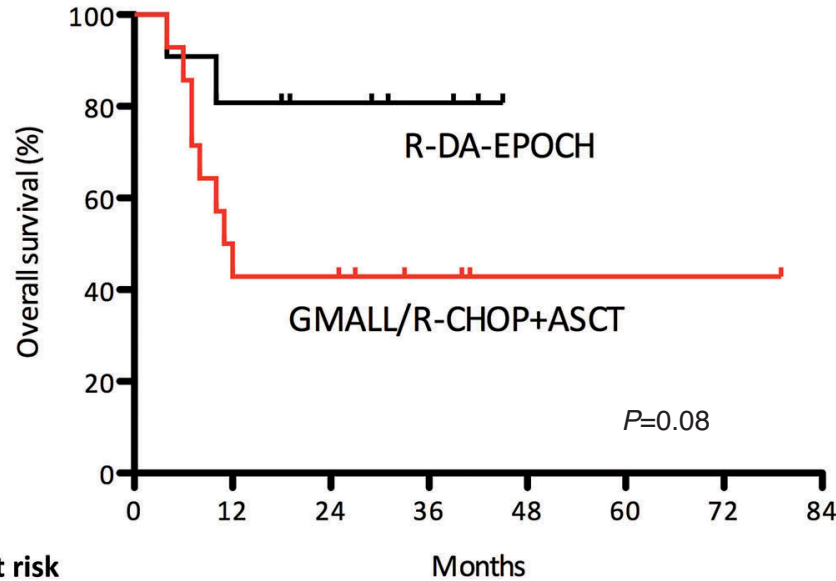

(number censored)

R-DA-EPOCH

GMALL/ R-CHOP+ASCT 11 (0) 8

$\begin{array}{cc}15 & 7 \\ (0) & (0)\end{array}$

6
$(3)$

5

0
$(9)$

0

0

6
$(0)$

1
$(5)$

(9)

$\begin{array}{cc}1 & 1 \\ (5) & (5)\end{array}$

Figure 4. Analysis of response to treatment with R-DAEPOCH. In the MYC-T and MYC-AMP subgroups, patients treated with R-DA-EPOCH showed an advantage in ORR and trend toward a better survival compared to patients treated with GMALL B-ALL/NHL 2002 protocol or RCHOP followed by autologous stem cell transplantation (ASCT).

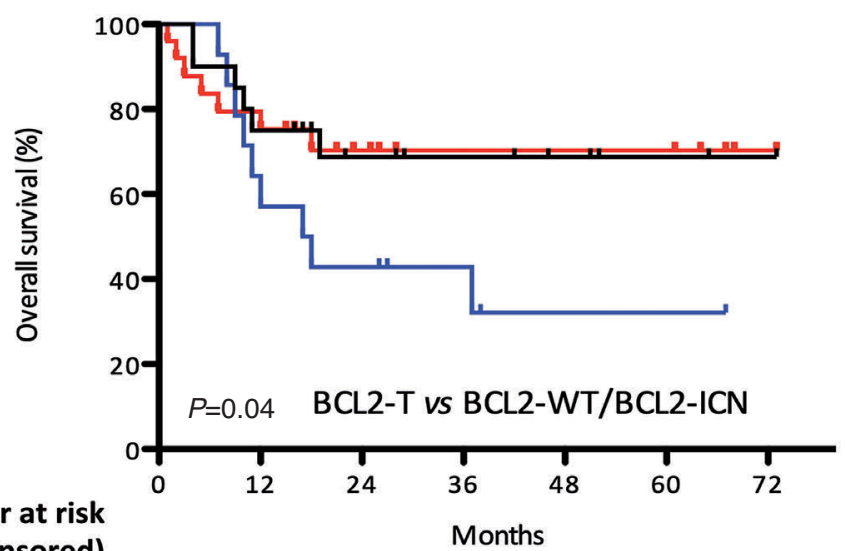

(number censored)

$\begin{array}{cccccccc}\text { BCL2-WT } & 20 & 15 & 10 & 8 & 5 & 2 & 1 \\ & (0) & (0) & (4) & (6) & (9) & (12) & (13) \\ \text { BCL2-ICN } & 25 & 19 & 10 & 7 & 7 & 7 & 1 \\ & (0) & (1) & (8) & (11) & (11) & (11) & (17) \\ \text { BCL2-T } & 14 & 9 & 6 & 4 & 2 & 2 & 0 \\ & (0) & (0) & (0) & (2) & (3) & (3) & (5)\end{array}$

\section{$\longrightarrow$ BCL2-WT \\ BCL2-ICN \\ BCL2-T}

Figure 5. Negative impact of $B C L 2$ translocation on the outcome of patients with MYC-ICN. BCL2-ICN did not influence survival of patients with MYC-ICN, whereas BCL2-T negatively influenced the outcome of these patients compared to BCL2-WT and BCL2-ICN patients. Notably, among patients with MYC-ICN and BCL2-T, the group with $>4$ copies had a significantly worse prognosis than patients with $\leq 4$ copies [median overall survival (OS) of 11 months compared to a 2.5 -year OS of $75 \%$, $P=0.004$ ] (data not shown). 
OS $32 \%$ vs. $70 \%, P=0.04$ ) (Figure 5), whereas BCL6-ICN and BCL6-T did not significantly impact on patient outcome compared to WT BCL6 (data not shown). Of note, among patients with MYC-ICN and BCL2-T, the group with $\geq 4$ MYC copies had a significantly worse prognosis than patients with $<4$ copies (median OS of 11 months compared to a 2.5 -year OS of $75 \%, \mathrm{P}=0.004$ ) (data not shown). Only one patient with MYC-AMP was positive for $B C L 2$ translocation; survival was seven months.

\section{Discussion}

MYC rearrangement is considered to confer a poor prognosis to DLBCL patients and to represent an adverse prognostic factor in patients treated with R-CHOP. In our study, the prevalence of MYC translocations was $8.8 \%$, in accordance with data from the literature..$^{10} \mathrm{~A}$ single-hit MYC aberration was present in $26 \%$ of patients, while $74 \%$ had classical DH/TH aberrations. Although a worse prognosis of patients with $\mathrm{DH} / \mathrm{TH}$ compared to $\mathrm{SH}$ DLBCL has been described, ${ }^{24,25}$ we could not confirm a significant difference in the outcome of $\mathrm{SH}$ versus $\mathrm{DH} / \mathrm{TH}$ patients, as reported also by Copie-Bergman. ${ }^{16}$ Among patients with MYC-T eligible for curative chemotherapy, $65 \%$ were treated with an intensified regimen, obtaining a slight advantage in terms of response rate but no significant advantage in survival compared to standard dose chemo-immunotherapy, confirming data reported by Petrich et al. ${ }^{26}$

In addition to $M Y C$ gene rearrangements, an increase in MYC copy number was observed in $16 \%$ of patients, a nearly 2 -fold more than that of MYC translocations. The presence of MYC-ICN has been analyzed in several studies; frequency ranged from $7 \%$ to $21 \%, 18,20,27-29$ but its prognostic significance is still controversial. Yoon reported ICN in $7 \%$ of 156 DLBCL patients, ${ }^{18}$ with an adverse prognostic significance, while Testoni et al. found an ICN of no more than 4 gene copies in 10\% of 166 patients, and the negative prognostic impact was limited to patients with a concomitant del (8p) chromosomal aberration. ${ }^{28}$ Valera et al. found 3-4 MYC ICN in 19\% and >4 MYC-ICN in 2\% of 176 patients, with a negative impact on outcome in the few patients with $>4$ MYC-ICN. ${ }^{20}$ In the group of 22 patients with $>4$ MYC ICN analyzed by Landsburg et al., neither the 2-year PFS (48\%) or OS (71\%) were significantly lower than those of patients with normal MYC. ${ }^{29}$ More recently, in a large study reported by Quesada on 663 DLBCL patients, $76(12 \%)$ had MYC-ICN, and 16\% of them had $>4$ extra-copies. The CR and OS of patients with MYC-ICN were significantly worse compared to patients with normal MYC gene, irrespective of the number of MYC extra-copies. ${ }^{27}$

A number of $M Y C$ copies $>4$ has been defined in some studies as MYC amplification. ${ }^{20,30}$ In the present study, we have analyzed the 61 patients with MYC-ICN by exactly enumerating the number of $M Y C$ extra-copies, defining as amplified those cases with an uncountable number of MYC-copies. The same criteria and terminology have been adopted in a recent study by Pophali et al..$^{31} \mathrm{We}$, like other authors, ${ }^{20,31}$ did not systematically use a chromosome 8 centromeric probe for this study. Nevertheless, we analyzed chromosome 8 in 11 cases with MYC-ICN, and no abnormal copies of chromosome 8 were detected, thus excluding polysomy as cause of MYC-ICN.

Our patients with 3 or 4 gene copies, accounting for more than $60 \%$ of MYC-ICN, had a more favorable outcome than patients with MYC-ICN $>4$, and their ORR and CRR were higher compared to the other FISH groups, and were not influenced by the type of treatment received as first-line. There was no difference in OS between patients with 3 or $4 M Y C$ gene copies. On the other hand, by stratifying them according to the exact number of MYC extra-copies, a negative correlation between an increasing number of MYC copies and survival was observed. Patients with MYC-ICN >7 had the worst prognosis, and patients with an amplification of MYC at FISH had a particularly aggressive disease and a dismal prognosis. Of note, the single MYC-AMP patient who did not show MYC protein positivity by immunohistochemistry was also the only patient who responded to treatment. Notably, a correlation between an excess of MYC copies, MYC protein overexpression and poor outcome has been previously described..$^{32}$ In our study, patients with MYCICN $>4$ seemed to have a more favourable outcome compared to MYC-T patients, whereas Quesada and colleagues observed the opposite result, although this outcome was not statistically significant in both studies. ${ }^{27}$

Taken together, our results show a prognostic role of the number of MYC extra-copies. In accordance with other studies, results underline that, among MYC-ICN, the presence of $>4$ MYC gene copies, and particularly of countless numbers of MYC as in MYC-AMP, is associated with a worse prognosis and does identify a category of patients with a prognosis similar to double-hit lymphoma. Of note, the 24 patients with $>4$ MYC copies represented $6.6 \%$ of our entire series, further supporting the potential usefulness of a routine use of FISH at diagnosis in DLBCL. ${ }^{12,13,33}$ We did not identify specific clinical characteristic of patients associated with the presence of different FISH patterns, except that a significant higher percentage of patients with BCLU histology clustered in the MYC-T group. Notably, 7 of 8 patients with BCLU carried MYC$\mathrm{T}$ and one patient MYC-AMP. Since 5 patients with BCLU and MYC-T had a double- or triple-hit lymphoma, they would now be defined as high grade B-cell lymphoma (HGBCL) with MYC and BCL2 and/or BCL6 translocations according to the updated 2016 WHO classification of lymphoid neoplasms.

Although there have been no published prospective trials in double-hit lymphoma, retrospective studies seem to suggest that aggressive induction regimens may confer a superior outcome. ${ }^{34}$ In a large retrospective series, patients receiving a Burkitt-like regimen (cyclophosphamide, vincristine, doxorubicin, methotrexate, ifosfamide, etoposide, cytarabine, CODOX-M/IVAC) and consolidation with ASCT appeared to have favorable outcomes over historical controls; however, the 2-year PFS was only $44 \%$, with early progressions precluding ASCT in $41 \%$ of patients. ${ }^{35}$ In another non-randomized retrospective study comparing R-CHOP with R-DA-EPOCH and other intensified regimens, response rates were higher for doseadjusted R-EPOCH. ${ }^{20,36}$

In addition to its retrospective nature, a major limitation of our study in evaluating the impact of different treatment strategies on lymphoma outcome was the heterogeneity of the regimens used, including ASCT, and the small number of patients in each subgroup with different MYC abnormalities. Moreover, the exclusion of patients not treated with curative intent does not allow the frequency of MYC abnormalities in these patients or their 
impact on the efficacy of less intensive treatments to be evaluated. In any case, the treatment choice was based on the individual clinician's decision.

Overall, no differences emerged between standard chemo-immunotherapy and more aggressive regimens both in CR achievement and in survival, particularly in the subgroup of patients with a limited number of $M Y C$ abnormalities $(\leq 4)$. On the other hand, the survival of patients with MYC-T, MYC-ICN >4 and MYC-AMP seemed to be superior if intensive treatments were used, and DA-EPOCH among intensive treatments seemed to be the most effective for patients with MYC-T and MYCAMP. Nevertheless, these retrospective data should be interpreted with caution, particularly in the absence of statistical significance; further studies are need in larger groups of patients and these results confirmed in prospective studies.

The present study further confirms that the occurrence of a $B C L-2$ translocation has a negative prognostic influence. In contrast to the presence of $M Y C$ extra-copies, the presence of extra-copies of $B C L-2$ and $B C L-6$ genes did not carry any adverse prognostic significance. Likewise, $B C L-2$ and $B C L-6$ extra-copies did not worsen the outcome of patients with MYC-ICN in the study by Quesada et al. ${ }^{27}$

In conclusion, our study shows that, in DLBCL patients, MYC extra-copies are more frequently detected by FISH studies than $M Y C$ translocations, highlighting the importance of FISH testing at diagnosis of DLBCL. While having 3-4 copies of MYC correlated with a high rate of treatment response and a good prognosis also with standard immuno-chemotherapy, lymphoma showing $>4$ copies of $M Y C$ had a more aggressive disease, comparable to MYC-translocated DLBCL, and may be more responsive to intensified treatment approaches. Further investigation is warranted to clarify the biological implications of numerical aberrations of $M Y C$ and the possible benefit of specific or intensified therapeutic strategies.

\section{Acknowledgments}

The authors would like to thank all doctors and nurses who provided patients' care at the Department of Hematology, ASST Spedali Civili di Brescia.

\section{References}

1. Swerdlow SH, Campo E, Pileri SA, et al. The 2016 revision of the World Health Organization classification of lymphoid neoplasms. Blood. 2016;127(20):2375-2391.

2. International Non-Hodgkin's Lymphoma Prognostic Factors Project. A predictive model for aggressive Non-Hodgkin's Lymphoma. N Engl J Med. 1993; 329(14):987-994.

3. Sehn LH, Berry B, Chhanabhai M, et al. The revised International Prognostic Index (RIPI) is a better predictor of outcome than the standard IPI for patients with diffuse large Bcell lymphoma treated with R-CHOP. Blood. 2015:109(5):1857-1862.

4. Green TM, Young KH, Visco C, et al. Immunohistochemical double-hit score is a strong predictor of outcome in patients with diffuse large B-cell lymphoma treated with rituximab plus cyclophosphamide, doxorubicin, vincristine, and prednisone. J Clin Oncol. 2012;30(28):3460-3467

5. Jaffe E, Harris N, Stein H, Vardiman J. Pathology and Genetics of Tumours of Haematopoietic and Lymphoid Tissues. WHO Classification of Tumours, Third Edition. 3. 2001;3.

6. Swerdlow SH, Campo E, Harris NL, et al. WHO Classification of Tumours, Fourth Edition. IARC WHO Classif Tumours. 2008;

7. Rosenwald A, Wright G, Chan WC, et al. The Use of Molecular Profiling to Predict Survival after Chemotherapy for Diffuse Large-B-Cell Lymphoma. N Engl J Med. 2002;346(25):1937-1947.

8. Hu S, Xu-Monette ZY, Tzankov A, et al. MYC/BCL2 protein coexpression contributes to the inferior survival of activated B-cell subtype of diffuse large B-cell lymphoma and demonstrates high-risk gene expression signatures: A report from the International DLBCL Rituximab-CHOP
Consortium Program. Blood. 2013; 121(20): 4021-4031

9. Kramer MH, Hermans J, Wijburg E, et al. Clinical relevance of BCL2, BCL6, and MYC rearrangements in diffuse large B-cell lymphoma. Blood. 1998:92(9):3152-3162.

10. Horn H, Ziepert M, Becher C, et al. MYC status in concert with BCL2 and BCL6 expression predicts outcome in diffuse large B-cell lymphoma. Blood. 2013;121(12):22532263

11. Klapper W, Stoecklein H, Zeynalova S, et al Structural aberrations affecting the MYC locus indicate a poor prognosis independent of clinical risk factors in diffuse large B-cell lymphomas treated within randomized trials of the German High-Grade NonHodgkin's Lymphoma Study Group (DSHNHL). Leukemia. 2008;22(12):2226 2229.

12. Savage KJ, Johnson $\mathrm{N}$ a, Ben-neriah S, et al. MYC gene rearrangements are associated with a poor prognosis in diffuse large B-cell lymphoma patients treated with R-CHOP chemotherapy. Blood. 2009;114(17):35333537 .

13. Barrans S, Crouch S, Smith A, et al. Rearrangement of MYC is associated with poor prognosis in patients with diffuse large B-cell lymphoma treated in the era of rituximab. J Clin Oncol. 2010;28(20):3360-3365.

14. Snuderl M, Kolman O, Chen Y-B, et al. B-cell Lymphomas with Concurrent IGH-BCL2 and MYC Rearrangements Are Aggressive Neoplasms with Clinical and Pathologic Features Distinct from Burkitt Lymphoma and Diffuse Large B-cell Lymphoma. Am J Surg Pathol. 2010;34(3):327-340

15. Campo E. MYC in DLBCL: Partners matter. Blood. 2015;126(22):2439-2440.

16. Copie-Bergman C, Cuillière-Dartigues $\mathrm{P}$ Baia $M$, et al. MYC-IG rearrangements are negative predictors of survival in DLBCL patients treated with immunochemotherapy: A GELA/LYSA study. Blood. 2015; 126(22):2466-2474.
17. Pedersen MO, Gang AO, Poulsen TS, et al $M Y C$ translocation partner gene determines survival of patients with large B cell lymphoma with MYC or double hit MYC/BCL2 translocations. Eur J Haematol. 2014;92(1):42-48.

18. Yoon S, Jeon Y, Paik J, et al. MYC translocation and an increased copy number predict poor prognosis in adult diffuse large B-cell lymphoma (DLBCL), especially in germinal centre-like B cell (GCB) type. Histopathology. 2008;53(2):205-217.

19. Stasik CJ, Nitta H, Zhang W, et al. Increased MYC gene copy number correlates with increased $m R N A$ levels in diffuse large B-cell lymphoma. Haematologica. 2010;95(4):597603

20. Valera A, López-Guillermo A, CardesaSalzmann T, et al. MYC protein expression and genetic alterations have prognostic impact in patients with diffuse large B-cell lymphoma treated with immunochemotherapy. Haematologica. 2013;98(10):1554-1562.

21. Hoelzer D, Walewski J, Hartmut D, et al Improved outcome of adult Burkitt lymphoma/leukemia with rituximab and chemotherapy : report of a large prospective multicenter trial. Blood. 2014;124(26):38703880.

22. Cheson BD, Pfistner B, Juweid ME, et al. Revised response criteria for malignant lymphoma. J Clin Oncol. 2007;25(5):579-586.

23. Kaplan EL, Meier P. Nonparametric Estimation from Incomplete Observations. J Am Stat Assoc. 1958;53(282):457-481.

24. Cohen JB, Geyer SM, Lozanski G, et al. Complete Response to Induction Therapy in Patients With Myc-Positive and Double-Hit Non-Hodgkin Lymphoma Is Associated With Prolonged Progression-Free Survival. Cancer. 2014;120(11):1611-1613

25. Landsburg DJ, Nasta SD, Svoboda J, Morrissette JJD, Schuster SJ. ' Double-Hit cytogenetic status may not be predicted by baseline clinicopathological characteristics 
and is highly associated with overall survival in B cell lymphoma patients. Br J Haematol. 2014;166(3):369-374.

26. Petrich AM, Gandhi M, Jovanvoic B, et al. Impact of induction regimen and stem cell transplantation on outcomes in patients with double-hit lymphoma: a large multicenter retrospective analysis. Blood. 2014;124(15):1-9

27. Quesada A, Medeiros L, Desai P, et al. Increased MYC copy number is an independent prognostic factor in patients with diffuse large B-cell lymphoma. Mod Pathol. 2017;30(12):1688-1697.

28. Testoni M, Kwee I, Greiner TC, et al. Gains of MYC locus and outcome in patients with diffuse large B-cell lymphoma treated with R-CHOP. Br J Haematol. 2011;155(2):274277.

29. Landsburg DJ, Falkiewicz MK, Petrich AM, et al. Sole rearrangement but not amplifica- tion of MYC is associated with a poor prognosis in patients with diffuse large $B$ cell lymphoma and B cell lymphoma unclassifiable. Br J Haematol. 2016;175(4): 631-640.

30. Testoni M, Zucca E, Young KH, Bertoni F. Genetic lesions in diffuse large B-cell lymphomas. Ann Oncol. 2015;26(6):1069-1080.

31. Pophali P, Marinelli LM, Ketterling RP, et al. High Level MYC Amplification in Aggressive B-Cell Lymphomas: Is It a Marker of Aggressive Disease? Blood. 2018;132(Suppl 1):1693.

32. Valentino C, Kendrick S, Johnson N, et al. Colorimetric In Situ Hybridization Identifies MYC Gene Signal Clusters Correlating With Increased Copy Number, mRNA, and Protein in Diffuse Large B-cell Lymphoma Carlo. Am J Clin Pathol. 2013;139(2):242254.

33. Swerdlow SH. Diagnosis of 'double hit' dif- fuse large B-cell lymphoma and B-cell lymphoma, unclassifiable, with features intermediate between DLBCL and Burkitt lymphoma: when and how, FISH versus IHC. Hematol Am Soc Hematol Educ Program. 2014;2014(1):90-99.

34. Friedberg JW. How I Treat How I treat double-hit lymphoma. Blood. 2017;130(5):590597.

35. Sun H, Savage K, Karsan A, et al. Outcome of Patients With Non-Hodgkin Lymphomas With Concurrent MYC and BCL2 Rearrangements Treated With CODOX M/IVAC With Rituximab Followed by Hematopoietic Stem Cell Transplantation. Clin Lymphoma Myeloma Leuk. 2015;15(6):341-348.

36. Oki Y, Noorani M, Lin P, et al. Double hit lymphoma: the $\mathrm{MD}$ Anderson Cancer Center clinical experience. Br J Haematol. 2014;166:891-901 